\title{
Comparison of Mental Health Components among Athlete and Non-athlete Adolescents
}

\author{
Zeinab Ghiami (Corresponding author) \\ Department of Sport Studies, Universiti Putra Malaysia, Malaysia \\ E-mail: ghiami.z@gmail.com \\ Karim Khalaghi \\ Hakim Nezami Institute of Higher Education, Iran \\ E-mail: karim.khalaghi@yahoo.com \\ Kim Geok Soh \\ Sports Academy, Faulty of Educational Studies, Universiti Putra Malaysia, Malaysia \\ E-mail: kims@putra.upm.edu.my \\ Samsilah Roslan \\ Faculty of Educational Studies, University Putra Malaysia, Malaysia \\ E-mail: Samsilah@upm.edu.my
}

Received: 02-06- 2015

Accepted: 23-07- 2015

Published: 31-07- 2015

doi:10.7575/aiac.ijkss.v.3n.3p.33

URL: http://dx.doi.org/10.7575/aiac.ijkss.v.3n.3p.33

\begin{abstract}
Background: Adolescence is a period of rapid biological and behavioral changes that may expand the risk of mental health issues. Objective: This study aimed to compare the mental health of male and female athletes and non-athletes among a high school student groups. Methodology: On this base 100 students ( 50 athletes and 50 non-athletes, $M_{a g e}=$ $16(\mathrm{SD}= \pm 1)$ ) were selected through multi stage random sampling and divided equally into four groups (female athlete / non-athlete, male athlete / non-athlete). General Health Questionnaire designed by Goldberg and Hiller (1979) was used for data collections. Results: The analysis of one-way ANOVA displayed significant differences between the mean scores in mental health among the groups in terms of mental health, $F(3,96)=39, P=.01)$ with less prevalence of these symptoms among athletes comparing to non-athletes. Conclusion: Increasing opportunities for students to take part in sport competitions can protect them against poor psychological well-being.
\end{abstract}

Keywords: Mental Health; Depression; Anxiety; Social dysfunction; Somatic

\section{Introduction}

Enhancing the physical and mental well-being of the individual is an important concern worldwide (World Health Organization, 2014). Well-being refers to physical, mental, and social prosperity and is perceived as crucial to human right. Mental well-being can also be seen as the emotional flexibility that empowers people to appreciate life and adapt to physical pain, stress and anxiety, while they are experiencing disappointment and sadness (Faulkner \& Taylor, 2005). Mental health has important effect on physical health as it has been demonstrated the way that people think has a significant effect on their physical wellbeing (Creek \& Lougher, 2011). Moreover, good mental health enables people to understand their intellectual and emotional potential to discover their abilities in social, school and working life.

That is, since everybody has psychological well-being needs, the need for mental health advancement is universal and of significance to everybody. Mental health issues influence $10-20 \%$ of children and youths around the world. Despite this, there is a disregards for well-being related to inability in this age group and their enduring impacts all through life (Penedo \& Dahn, 2005). In addition, mental health needs of children and adolescents are overlooked particularly in developing countries. The most crucial period of the individual's life is childhood and adolescence, since physiological and psychological changes in these period are at the highest level (Hallal, Victora, Azevedo, \& Wells, 2006; VicenteRodríguez, 2006). Likewise, life style and healthy/unhealthy behavior and habits are established during these years, which may determine their adulthood lifestyle.

Adolescents have the highest level of mental health symptoms among all age groups (Merikangas et al., 2010). The period of adolescence is characterized by fast physical and behavioral changes (Duckett, 2001). These changes amplify the danger of psychological well-being issues. Considering the importance of adolescence period for advancing a healthy lifestyles (Breinbauer, 2005); focusing on this age group's mental health is justified. 
The investigation of effect of physical activity on the psychological well-being has significant interest from developmental and theoretical perspectives. In addition, physical activities provide a context for personal assessment and growth. Further dedicated sport participation appears to be useful in the treatment of adolescents with mental health problems (Steiner, McQuivey, Pavelski, Pitts, \& Kraemer, 2000).

The results of previous studies provide evidence that sport participation has significant impacts over psychological and physical wellness. According to Penedo and Dahn (2005), participants in physical activity interventions display better physical and psychological health and higher quality of life style. Also it will improve well-being related to personal satisfaction, better functional capacity and better mind states. Considering that most of the research has focused on university students or expert athletes, little information is available for the school level athlete.

Physical activity among adolescents in school has beneficial outcomes for depression, anxiety, mood status, and selfesteem, and appears to be additionally to be connected with a higher academic performance. Therefore, health promotion policies and physical activity projects should enhance mental health among students. Schools play a vital role by recognizing adolescents with low level of mental health and by promoting positive health behaviors, for example, encouraging them to attend in school sport competitions. (Ortega, Ruiz, Castillo, \& Sjöström, 2008). Therefore, the purpose of this study was to determine and compare level of mental health among high school athlete and non-athlete students.

\section{Method}

\subsection{Participants}

The research population for the current study was male and female students ( $M_{\text {age }}=16$ years, age range: $15-17$ years) from a high school in Quchan, Iran. Initial screening was conducted by implementing a survey base on sport background questionnaire to identify the population of athlete and non-athlete students. 100 students were randomly selected as the participants and were assigned to either the athlete and non-athlete groups with 50 students in each group. This study assessed students' current exercise level, their psychological constructs related to mental health, such as somatic, anxiety, social, and depression. Ethical approval for the study was obtained from the Ministry of Education, in Iran. The subjects were given a clear explanation of the objectives of the study, as well as the potential risks involved, and parental consent forms were obtained for all subjects.

\subsection{Instruments}

Two sets of questionnaires (including screening questionnaire) were used to gather the data on health and alienation status. The scaled version of the General Health Questionnaire of Goldberg and Hillier (1979) was used to measure the level of mental health in students. This questionnaire consists of 4 subscales: somatic symptoms, anxiety and insomnia, social dysfunction and severe depression. Reliability analysis was completed for on all items in the instrument which used Likert scale measurement. The validity of these scales was provided through pilot study, and the performance of the whole 28-item questionnaire as a screening test was evaluated. Grading was based on a four-point Likert scale including 0 "never", 1 "sometimes", 2 "often", 3 "usually". At every scale grades above 6 and the sum of the scores above 22 indicated signs of mental issues.

\subsection{Statistical Analysis}

The Statistics Package for Social Science (SPSS) for Windows version 21 was used to analyze the data. Firstly, data was tested for normal distribution with the Kurtosis and Skewness test and for homogeneity of variances with Levene's test (Meyers, Gamst, \& Guarino, 2006; Pallant, 2010). The data was analyzed using descriptive statistics as well as oneway ANOVA to determine whether the athletes and non-athletes (males and females) are different in terms of mental health and related constructs.

\section{Results}

The main objective of the current study was to compare athletes and non-athlete (F, M) high school students in terms of their mental health. To this end, a one-way ANOVA was conducted to test the difference between the mean scores of four group students' mental health construct. As summarized in Table 2, the results of one-way ANOVA displayed a statistically significant difference between the mean scores in mental health among the groups, $F(3,96)=39, P=.01)$

Table 1. Result of ANOVA for Mental Health Components

\begin{tabular}{lccccc}
\hline & Sum of Squares & Df & Mean Square & F & P \\
\hline Somatic & 2629.47 & 3 & 876.49 & 13.72 & 0.01 \\
Anxiety & 369.95 & 3 & 123.31 & 7.51 & 0.01 \\
Social dysfunction & 1208.72 & 3 & 402.90 & 11.11 & 0.01 \\
Depression & 4508.24 & 3 & 1502.74 & 53.88 & 0.01 \\
Mental Health & 15969.95 & 3 & 5323.37 & 38.86 & 0.01 \\
\hline
\end{tabular}


In addition, a one-way between group analysis of variance was conducted to explore the differences between mean scores of mental health among athletes and non-athletes students. Participants were divided into four groups (Group 1: female non-athlete, Group 2: female athlete, Group 3: male non-athlete, and Group 4: male athlete). Results showed a statistically significant difference $(p=.01)$ in mental health scores for the four groups. Post-hoc comparison using the Tukey HSD test indicated the mean score for Group $1(\mathrm{M}=59.84, \mathrm{SD}=17.43)$, Group $2(\mathrm{M}=27.36, \mathrm{SD}=9.17)$, Group $3(\mathrm{M}=58.8, \mathrm{SD}=8.11)$ and Group $4(\mathrm{M}=30.16, \mathrm{SD}=9.68)$ were significantly different.

Table 2. Descriptive Analysis of Mental Health

\begin{tabular}{|c|c|c|c|c|c|c|c|c|}
\hline & \multicolumn{4}{|c|}{ Athlete } & \multicolumn{4}{|c|}{ Non-Athlete } \\
\hline & \multicolumn{2}{|c|}{ Male } & \multicolumn{2}{|c|}{ Female } & \multicolumn{2}{|c|}{ Male } & \multicolumn{2}{|c|}{ Female } \\
\hline & $M$ & $S D$ & $M$ & $S D$ & $M$ & $S D$ & $M$ & $S D$ \\
\hline Somatic & 6.84 & 2.21 & 2.72 & 4.13 & 15.84 & 10.51 & 12.96 & 11.08 \\
\hline Anxiety & 7.48 & 4.52 & 6.00 & 4.44 & 11.28 & 3.62 & 8.76 & 3.50 \\
\hline Social dysfunction & 11.88 & 2.80 & 13.28 & 3.84 & 20.80 & 6.32 & 17.08 & 9.07 \\
\hline Depression & 3.96 & 3.18 & 5.36 & 5.72 & 10.92 & 3.73 & 21.04 & 7.39 \\
\hline Mental health & 30.16 & 9.68 & 27.36 & 9.17 & 58.80 & 8.11 & 59.84 & 17.43 \\
\hline
\end{tabular}

Results showed that female athletes had a higher level of mental health compared to the other three groups, while the non-athletic girls had the highest rates of mental health symptoms. The male athletes also had higher levels of mental health compared to non-athletes males.

Data analysis also showed a significant difference in terms of physical symptoms among athletic and non-athletic girls and boys, $F(3,96)=13.72, p=.01$. Post hoc comparisons using the Tukey HSD test indicates that the mean score for athlete females (2.72) was significantly different from non-athlete females (12.96) and non-athlete males (15.84) in term of physical symptoms. However, athlete males (6.84) did not significantly differ from the athlete females and both groups had less physical symptoms. Combined, these results suggest athlete students in both gender experiences less physical symptoms comparing with non-athletes. However, it should be noted that even though athlete males have less physical symptoms comparing non-athlete, they showed a risk level of somatic construct.

Data analysis also showed a significant difference in terms of components of anxiety among athletic and non-athletic girls and boys, $F(3,96)=7.51, p=.01$. Post hoc comparisons using the Tukey HSD test indicates that the mean score of athlete male (7.48) was significantly different from non-athlete male (11.28) and non-athlete females (8.76) in term of anxiety. However, athlete female and non-athlete female was not significantly different. Combined, these results show a lower level of anxiety among females comparing to males, although physical activity did not contribute to the level of females' anxiety. Specifically, our results indicate a gender difference in terms of anxiety and sleep disorder with a lower level of them among females. However, it should be noted that non-athlete males are at the higher risk of the anxiety and sleep disorder comparing non-athlete females. These results show that female athletes are at a more favorable situation than others.

Results of the comparison between male and female athlete and non- athletes in terms of social dysfunction indicated a significant difference in terms of social dysfunction among the groups, $F(3,96)=11.11, p=.01$. Post hoc comparisons using the Tukey HSD test indicates that the mean score of athlete males $(\mathrm{M}=11.88)$ was significantly different from non-athlete males $(M=20.80)$ and non-athlete females $(M=17.08)$ in term of social dysfunction. However, athlete females $(M=13.28)$ and non-athlete females $(M=17.08)$ were not significantly different. Taken together, these results show a high risk level of social dysfunction among non-athlete males comparing to the other three groups, although physical activity did not contribute to the level of females' social dysfunction. Specifically, our results indicated that there are no gender differences in terms of social functioning. These results show that athlete males are at a more favorable situation than others.

There was also a significant difference between female and male athletes and non-athletes in terms of their depression. Analysis of variance showed a significant difference in terms of depression among groups, $F(3,96)=53.88, p=.01$. Post hoc comparisons using the Tukey HSD test indicated that the mean score of athlete males (3.96) and athlete females 5.36 were significantly different from the mean score of non-athlete females (21.04) and non-athlete males (10.92) in terms of depression. The findings also showed a significant difference among females and males, with a higher risk level of depression for females. An overview of the comparison between girls and boys showed a significant gender differences in terms of depression, athlete male were in the optimal position in terms of depression and nonathletic girls are in an undesirable situation. 


\section{Discussion}

The current study investigated the difference between athlete and non- athlete students during their high school in terms of each of physical symptoms including anxiety, social dysfunction and depression. According to the results, there was a statistically significant difference among athlete and non-athlete in all four mental health indicators with mental health of male athlete being higher than the other three groups. The non-athletic girls were in the worst position, with the highest rates of mental health symptoms.

Students who have been considered as athlete during high school showed lower physical and mental symptoms, like depression, anxiety, and higher mental health compared with non-athlete students. Participation in sport teams and competitions may provide students with opportunity to communicate with their peers and coaches and to feel connected to their school (Brettschneider, 2001), all of which can impact psychological wellness decidedly (McBride et al., 1995). According to Boone and Leadbeater (2006), participation in sport competition can be beneficial in improving social acceptance and body satisfaction. Sport competitions may also enhance self-efficacy, emotional intelligent, selfconfidence, and life quality, which leads to better psychological well-being (Pyle, Mc Quivey, Brassington, \& Steiner, 2003; Snyder et al., 2010).

In spite of the fact that the components supporting this affiliation should be recognized experimentally, it is possible that the focused nature and pressure load/ high pressure of specific games activate neuro protective impacts that prevent poor emotional well-being (Collins \& Fitterling, 2009). In view of these findings, youths ought to be urged to take part in some games at school to accumulate positive effects in their adulthood. The results of the current study is in line with findings by (Emami, Ghazinour, Rezaeishiraz, \& Richter, 2007) which showed a high percentage of high school students experience mental problems, with girls experiencing such disorders more frequently than boys.

Moreover, the findings of the current study are in contrast with a study by Gulliver, Griffiths, Mackinnon, Batterham, and Stanimirovic (2015) which showed $46.4 \%$ of athletes were experiencing symptoms of at least one of the mental health problems assessed. Tin their study athlete showed the same level of symptoms of mental health problems with non-athletes. However, this similarity in the mental health symptoms can be because of some demographic differences between athletes and non-athletes or the effect of self-selection of respondents.

\section{Conclusion}

As for the results of this study indicating that psychological problems were less in athletes, it can be concluded that physical activity as an easy and inexpensive strategy can be used in schools to increase the level of mental health among students. Specifically, our results suggest that when students engage in sport activities their symptoms related to mental health are reduced. Increasing opportunities for students to take part in sport competitions can protect them against poor psychological well-being.

\section{References}

Boone, E. M., \& Leadbeater, B. J. (2006). Game on: Diminishing risks for depressive symptoms in early adolescence through positive involvement in team sports. Journal of Research on Adolescence, 16(1), 79-90.

Breinbauer, C. (2005). Youth: Choices and change: Promoting healthy behaviors in adolescents (Vol. 594): Pan American Health Org.

Brettschneider, W.-D. (2001). Effects of sport club activities on adolescent development in Germany. European Journal of Sport Science, 1(2), 1-11.

Collins, K. A., \& Fitterling, H. L. (2009). Physical exercise and depression. Mount Sinai Journal of Medicine: A Journal of Translational and Personalized Medicine, 76(2), 204-214.

Creek, J., \& Lougher, L. (2011). Occupational therapy and mental health (4 ed.). U.S: Elsevier Health Sciences.

Duckett, M. (2001). Migrants' right to health: Joint United Nations Programme on HIV/AIDS.

Emami, H., Ghazinour, M., Rezaeishiraz, H., \& Richter, J. (2007). Mental health of adolescents in Tehran, Iran. Journal of Adolescent Health, 41(6), 571-576.

Faulkner, G. E., \& Taylor, A. H. (2005). Exercise, health and mental health: Emerging relationships: Taylor \& Francis. Goldberg, D. P., \& Hillier, V. F. (1979). A scaled version of the General Health Questionnaire. Psychological medicine, 9(01), 139-145.

Gulliver, A., Griffiths, K. M., Mackinnon, A., Batterham, P. J., \& Stanimirovic, R. (2015). The mental health of Australian elite athletes. Journal of Science and Medicine in Sport, 18(3), 255-261.

Hallal, P. C., Victora, C. G., Azevedo, M. R., \& Wells, J. C. (2006). Adolescent physical activity and health. Sports Medicine, 36(12), 1019-1030.

McBride, C. M., Curry, S. J., Cheadle, A., Anderman, C., Wagner, E. H., Diehr, P., \& Psaty, B. (1995). School-Level Application of a Social Bonding Model to Adolescent Risk-Taking Behavior. Journal of School Health, 65(2), 63-68.

Merikangas, K. R., He, J.-p., Burstein, M., Swanson, S. A., Avenevoli, S., Cui, L., . . Swendsen, J. (2010). Lifetime prevalence of mental disorders in US adolescents: results from the National Comorbidity Survey Replication- 
Adolescent Supplement (NCS-A). Journal of the American Academy of Child \& Adolescent Psychiatry, 49(10), 980989.

Meyers, L. S., Gamst, G., \& Guarino, A. J. (2006). Applied multivariate research: Design and interpretation. London: Sage.

Ortega, F., Ruiz, J., Castillo, M., \& Sjöström, M. (2008). Physical fitness in childhood and adolescence: a powerful marker of health. International journal of obesity, 32(1), 1-11.

Pallant, J. (2010). SPSS survival manual: A step by step guide to data analysis using SPSS. Melborn: McGraw-Hill International.

Penedo, F. J., \& Dahn, J. R. (2005). Exercise and well-being: a review of mental and physical health benefits associated with physical activity. Current opinion in psychiatry, 18(2), 189-193.

Pyle, R. P., Mc Quivey, R. W., Brassington, G. S., \& Steiner, H. (2003). High school student athletes: Associations between intensity of participation and health factors. Clinical Pediatrics, 42(8), 697-701.

Snyder, A. R., Martinez, J. C., Bay, R. C., Parsons, J. T., Sauers, E. L., \& Valovich McLeod, T. C. (2010). Healthrelated quality of life differs between adolescent athletes and adolescent nonathletes. J Sport Rehabil, 19(3), $237-248$.

Steiner, H., McQuivey, R. W., Pavelski, R., Pitts, T., \& Kraemer, H. (2000). Adolescents and sports: risk or benefit? Clinical Pediatrics, 39(3), 161-166.

Vicente-Rodríguez, G. (2006). How does exercise affect bone development during growth? Sports Medicine, 36(7), 561-569.

World Health Organization. (2014). Mental Health Atlas. 